\title{
Methionine and valine activate the mammalian target of rapamycin complex 1 pathway through heterodimeric amino acid taste receptor (TAS1R1/TAS1R3) and intracellular $\mathrm{Ca}^{2+}$ in bovine mammary epithelial cells
}

\author{
Y. Zhou, ${ }^{*} \dagger$ Z. Zhou, $\ddagger^{1}$ J. Peng, ${ }^{*}$ and J. J. Loor $\dagger^{1}$ \\ *Department of Animal Nutrition and Feed Science, College of Animal Science and Technology, Huazhong Agriculture University, Wuhan, \\ Hubei, China 430070 \\ †Mammalian NutriPhysioGenomics, Department of Animal Sciences and Division of Nutritional Sciences, University of Illinois, Urbana 61801 \\ fDepartment of Animal and Veterinary Sciences, Clemson University, Clemson, SC 29634
}

\begin{abstract}
Amino acids play a key role in regulating milk protein synthesis partly through activation of the mammalian target of rapamycin (mTOR) signaling pathway. However, the involvement of extracellular AA sensing receptors in this process is not well understood. In nonruminants, it is well established that the AA taste 1 receptor member $1 / 3$ (TAS1R1/TAS1R3) heterodimer contributes to the sensing of most L-AA. Whether this receptor is functional in bovine mammary cells is unknown. The objective of this study was to determine essential AA signaling through TAS1R1/TAS1R3 and their roles in regulating mTOR signaling pathway and casein mRNA abundance in primary bovine mammary epithelial cells and the Mac-T cell line. The bovine mammary epithelial cells were stimulated with complete Dulbecco's modified Eagle's medium (+EAA), medium without EAA (-EAA), or medium supplemented with only 1 of the 10 essential AA, respectively. The nonessential AA levels were the same across all treatments. Small interference RNA targeting TAS1R1 were designed and transfected into bovine primary mammary epithelial cells (bPMEC). Supplementation of a complete mixture of essential AA or Arg, Val, Leu, His, Phe, Met, and Ile individually led to greater mTOR phosphorylation. Phosphorylation of ribosomal protein S6 kinase $\beta-1$ was greater in the presence of Val, Leu, Trp, Met, and Ile. Valine, Leu, Met, and Ile led to greater eIF4E-binding protein 1 phosphorylation. Although +EAA and a few individual AA tested induced increases in intracellular calcium, Met and Val were the most potent. Knockdown of TAS1R1 decreased intracellular calcium in bPMEC cultured with both Val and Met. Phosphorylation of mTOR, ribosomal protein S6
\end{abstract}

\footnotetext{
Received January 16, 2018.

Accepted August 14, 2018.

${ }^{1}$ Corresponding authors: zzhou3@clemson.edu and jloor@illinois
} . $\mathrm{edu}$ kinase $\beta-1$, and eIF4E-binding protein 1 was lower when TAS1R1 was knocked-down in bPMEC supplemented with Val and Met. In addition, small interference RNA silencing of TAS1R1 resulted in lower $\beta$-casein (CSN2) abundance. The TAS1R1/TAS1R3 receptor may sense extracellular AA and activate mTOR signaling in bovine mammary cells, likely by elevating intracellular calcium concentration. This mechanism appears to have a role in Met- and Val-induced changes in CSN2 mRNA abundance. Further in vivo studies will have to be performed to assess the relevance of this mechanism in the mammary gland.

Key words: amino acids, lactation, ruminant, dairy cow

\section{INTRODUCTION}

Lactating mammary gland drains free AA from the circulation for milk protein synthesis (Shennan et al., 1998). In addition to the well-established role of AA as building blocks for protein synthesis, recent in vitro results demonstrated the regulatory role they play by inducing alterations in upstream regulatory pathways such as mammalian target of rapamycin (mTOR) signaling (Appuhamy et al., 2012). In agreement with in vitro results, studies in vivo also highlighted the regulatory role of AA on milk protein synthesis; for instance, when supplemented in rumen-protected form, particularly the indispensable AA Lys and Met, these AA led to enhanced milk protein yield (Nichols et al., 1998; Overton et al., 1998; Socha et al., 2005; Ordway et al., 2009; Trinacty et al., 2009; Broderick and Muck, 2009; Patton, 2010; Appuhamy et al., 2011; Lee et al., 2012; Osorio et al., 2013; Giallongo et al., 2015; Batistel et al., 2017; Zhou et al., 2017b). Correspondingly, deprivation of all AA or removing Leu or Ile individually reduced milk protein synthesis (Appuhamy et al., 2012).

The AA-induced stimulation of protein synthesis is partly mediated by the mammalian target of rapamycin complex 1 (mTORC1) pathway (Gulati et 
al., 2008; Appuhamy et al., 2012). When activated by AA, mTOR catalyzes phosphorylation of ribosomal protein S6 kinase $\beta-1$ (S6K1) and eIF4E-binding protein 1 (4EBP1; Wang and Proud, 2006). Branchedchain AA, in particular Leu, are potent activators of mTORC1 (Monirujjaman and Ferdouse, 2014). In bovine mammary tissue, Ile and Thr enhanced mTOR phosphorylation, and Ile increased ribosomal protein S6K1 phosphorylation linearly (Arriola Apelo et al., 2014). In Mac-T cells, the omission of only Ile, Arg, or Leu reduced phosphorylation of mTORC1 by 57 , 49, and 47\%, respectively (Appuhamy et al., 2012). Although AA transporter-induced mechanisms leading to mTORC1 signaling activation have been demonstrated in nonruminants, to our knowledge few such reports exist in bovine mammary epithelial cells. A study recently revealed that sestrin 2 negatively regulates cell proliferation and casein synthesis by inhibiting the AA-mediated mTORC1 pathway in cow mammary epithelial cells (Luo et al., 2018). Although induction of changes in protein synthesis have been well characterized in bovine mammary cells, additional mechanisms of AA action on mTORC1 merit further study.

Recent studies in nonruminants revealed a novel nutrient-sensing function for $\mathrm{G}$ protein-coupled receptors (GPCR; Nelson et al., 2002; Wauson et al., 2015). Originally known as taste-specific GPCR, the taste 1 receptor member 1 (TAS1R) $1 / 3$ is composed of a heterodimer with a taste-specific TAS1R1 and TAS1R3 GPCR. By promoting intracellular calcium $\left(\left[\mathbf{C a}^{2+}\right] \mathbf{i}\right)$ concentration and activating extracellular signal-regulated kinases 1 and 2 (ERK1/2), TAS1R1/TAS1R3 can regulate mTORC1 and, hence, serve as a sensor of AA availability upstream of mTORC1 signaling (Wauson et al., 2013). The mTOR upstream regulatory role of TAS1R1/TAS1R3 was recently demonstrated in various models [e.g., pancreatic $\beta$ cells (Wauson et al., 2015) and myoblasts (C2C12; Zhou et al., 2016)]. In fact, Met administration promoted myotube-related protein synthesis in $\mathrm{C} 2 \mathrm{C} 12$ cells by increasing $\left[\mathrm{Ca}^{2+}\right] \mathrm{i}$ concentration and activating ERK1/2, which enhanced mTORC1 signaling (Zhou et al., 2016).

At least in nonruminants, ligand specificity for TAS1R1/TAS1R3 appears to be species-dependent. For instance, human TAS1R1/TAS1R3 responded specifically to L-Glu, whereas in mouse the receptor was activated by Ser, Arg, Thr, Ala, Met, Gln, and Gly (Li et al., 2002; Nelson et al., 2002; Toda et al., 2013). Therefore, although TAS1R1/TAS1R3 knock-down was shown to decrease AA-induced mTORC1 signaling and $\beta$-casein (CSN2) mRNA and protein synthesis in mouse mammary epithelial cells (Wang et al., 2017), it is unknown which EAA activate TAS1R1/TAS1R3, and subsequently mTORC1 signaling, or whether these $\mathrm{AA}$, as ligands of T1R1/T1R3, regulate mRNA abundance of CSN2 in mammary epithelial cells. Thus, the main objective of the present study was to investigate the AA-sensing function of TAS1R1/TAS1R3 in the context of the mTORC1 signaling pathway in bovine mammary epithelial cells and to examine the association of these signaling mechanisms with mRNA abundance of casein.

\section{MATERIALS AND METHODS}

\section{Cell Culture and Treatment}

The cell culture was performed using bovine primary mammary epithelial cells (bPMEC; provided by M. Z. Wang, College of Animal Science and Technology, Yangzhou University, Yangzhou, Jiangsu, P.R. China) and the nonsecretory immortalized bovine mammary epithelial cell line Mac-T. Cells were seeded and cultured in 6-well plates at $37^{\circ} \mathrm{C}$ and $5 \% \mathrm{CO}_{2}$ in Minimum Essential Medium/Earle's Balanced Salts HyQ (MEM/ EBSS, HyClone, GE Life Sciences, Pittsburgh, PA) with insulin $(5 \mathrm{mg} / \mathrm{L}$, I6634, Sigma-Aldrich, St. Louis, MO), hydrocortisone (1 mg/L, H0888, Sigma-Aldrich), transferrin (5 mg/L, T1428, Sigma-Aldrich), ascorbic acid $(5 \mu \mathrm{mol} / \mathrm{L}, \mathrm{A} 4544$, Sigma-Aldrich), sodium acetate (5 mmol/L, S5636, Sigma), and penicillin/ streptomycin (10 mL/L, sv30010, HyClone). The basal medium was supplemented with fetal bovine serum (10\%, Gibco, Thermo Fisher Scientific, Waltham, MA), growth-promoting hormones $(1 \mathrm{mg} / \mathrm{L}$ of progesterone, P8783, Sigma-Aldrich), lactalbumin (0.05\%, L5385, Sigma-Aldrich), and $\alpha$-lactose $(0.05 \%, 47287-U$, SigmaAldrich; Kadegowda et al., 2009a).

At approximately $80 \%$ confluence, cells were starved overnight in serum-free complete Dulbecco's modified Eagle's medium (DMEM; catalog no.11965-092, Gibco, Thermo Fisher Scientific) followed by $2 \mathrm{~h}$ of incubation in AA-free Krebs-Ringer's solution (KRBH; catalog no. J67839AP, Alfa Aesar, Haverhill, MA) supplemented with $0.1 \%$ BSA. Treatments were complete DMEM containing $(\mathrm{mmol} / \mathrm{L}) 0.40 \mathrm{~L}-\mathrm{Arg}, 0.2 \mathrm{~L}$ His, 0.80 L-Ile, 0.80 L-Leu, 0.80 L-Lys, 0.20 L-Met, 0.40 L-Phe, $0.80 \mathrm{~L}-\mathrm{Thr}, 0.048 \mathrm{~L}-\mathrm{Trp}$, and $0.80 \mathrm{~L}-\mathrm{Val}$, which served as the positive control treatment (+EAA); DMEM devoid of all EAA (custom medium from Gibco, Thermo Fisher Scientific, formula no. 08-5004EL), which served as the negative control treatment (-EAA); and 10 different media each supplemented with a single EAA at concentrations equal to that in +EAA. Concentration of dispensable AA were the same for all treatments. Individual EAA (L-isomer) 
purchased from Sigma-Aldrich were supplemented to the -EAA medium. Cells were harvested after incubation for $30 \mathrm{~min}$. To induce CSN2 mRNA, all treatment media were lactogenic as described by Kadegowda et al. (2009b) except that high-glucose Dulbecco's modified Eagle's medium (HG-DMEM, HyClone) devoid of EAA (custom made from Gibco, Thermo Fisher Scientific) was used to replace Minimum Essential Medium/ Earle's Balanced Salts HyQ. The lactogenic medium was devoid of fetal bovine serum and was supplemented with BSA (1 g/L) and prolactin $(2.5 \mathrm{mg} / \mathrm{L})$. Casein mRNA was undetectable without lactogenic medium. The induction medium treatments were complete RPMI 1640 (catalog no. 11875-093, Gibco, Thermo Fisher Scientific) medium, control; RPMI 1640 medium devoid of all AA except glutamine; and RPMI 1640 medium only devoid of EAA.

\section{RNA Interference}

Small interfering RNA (siRNA) oligomers targeting TAS1R1 and scrambled oligomer (si-control) were purchased from Integrated DNA Technologies (Coralville, IA). The target sequences of TAS1R1 were 5-GGUUCAGCAUCGAGGAGAUAAACAA-3 (si1), 5-UCAGUAUUGCUGGACAUAAAUACGA-3 (si2), and 5-CAUCUCUAGUCACAUCAACAGUGTG-3 (si3). The bPMEC were transiently transfected with si-control or siRNA targeting TAS1R1 with Lipofectamine RNAiMAX (Life Technologies, Ghent, Belgium) according to the manufacturer's protocol (https: //assets.fishersci.com/TFS-Assets/LSG/manuals/ Lipofectamine_RNAiMAX_Reag_protocol.pdf). Three microliters of RNA interference duplex $(10 \mu M)$ in 150 $\mu \mathrm{L}$ of Opti-MEM (Cat. No. 31985-062, Thermo Fisher Scientific) was mixed with $9 \mu \mathrm{L}$ of Lipofectamine RNAiMAX in $150 \mu \mathrm{L}$ of Opti-MEM. The mixture was mixed gently and incubated for 5 to $10 \mathrm{~min}$ at room temperature before addition of $300 \mu \mathrm{L}$ of siRNA-reagent mix into each well. Forty-eight hours after transfection, sequential experiments to characterize molecular response were performed.

\section{Mammary Biopsies}

All procedures involving animals received approval from the Institutional Animal Care and Use Committee at the University of Illinois. Six to 8 multiparous Holstein cows from the University of Illinois dairy herd were used for biopsy at $-30,-15,1,15,30,60$, and $120 \mathrm{~d}$ relative to parturition. Cows were housed in a ventilated, enclosed barn during the dry period $(8 \mathrm{~h}$ light:16 h dark photoperiod) and had access to sandbedded freestalls until $3 \mathrm{~d}$ before expected parturition, when they were moved to individual maternity pens bedded with straw until parturition. After parturition, cows were housed in a tiestall barn under ambient photoperiod conditions through the end of the study. Prior to biopsy, cows received a general anesthetic (xylazine; $0.025 \mathrm{mg} / \mathrm{kg}$ of BW of a $20 \mathrm{mg} / \mathrm{mL}$ solution; AnaSed, AKorn Inc., Vernon Hills, IL) before applying a local anesthetic ( $5 \mathrm{~mL}$, lidocaine- $\mathrm{HCl}, 2 \%$ solution; catalog no. 118RX, Vet One, Boise, ID) on the midsection of the right or left rear quarter. Subsequent biopsies alternated between right or left rear quarters of mammary gland. Mammary tissue was harvested as described in a previous studies (Bionaz and Loor, 2011). Tissue ( $\sim 25$ $\mathrm{mg}$ ) was frozen immediately in liquid $\mathrm{N}$ and later used for total RNA extraction. Pre- and postpartal biopsies were performed sequentially before the morning feeding. Six to 8 cows at each sampling time point were biopsied. All cows had ad libitum access to a mixed ration balanced to meet the nutrient requirements of the cows during late pregnancy and early lactation. Fresh water was available to cows at all times during the day. Cows were fed individually once daily pre- and postpartum at $0630 \mathrm{~h}$.

\section{RNA Extraction, cDNA Synthesis, and Real-Time PCR Analysis}

Total RNA extraction was performed with the miRNeasy kit (Qiagen, Valencia, CA) according to the manufacturer's instructions (https://assets.fishersci .com/TFS-Assets/LSG/manuals/purelink_microRNA _man.pdf). Reverse transcription was performed essentially as described previously (Osorio et al., 2014). For qPCR, $4 \mu \mathrm{L}$ of diluted cDNA was combined with 6 $\mu \mathrm{L}$ of a mixture composed of $5 \mu \mathrm{L}$ of $1 \times \mathrm{SYBR}$ Green Master Mix (Quanta, Gaithersburg, MD), $0.4 \mu \mathrm{L}$ each of $10 \mu \mathrm{M}$ forward and reverse primers, and $0.2 \mu \mathrm{L}$ of RNase-free water. The qPCR was performed in $10-\mu \mathrm{L}$ reactions containing $4 \mu \mathrm{L}$ of diluted cDNA and $6 \mu \mathrm{L}$ of a mixture composed of $5 \mu \mathrm{L}$ of $1 \times$ SYBR Green Master Mix $(0.4 \mu \mathrm{L}$ each of $10 \mu M$ forward and reverse primers, and $0.2 \mu \mathrm{L}$ of DNase/RNase-free water; Quanta, Gaithersburg, MD). Reaction mixtures were preheated at $95^{\circ} \mathrm{C}$ for $5 \mathrm{~min}$, followed by 40 cycles of melting at $94^{\circ} \mathrm{C}$ for $15 \mathrm{~s}$, and annealing at $60^{\circ} \mathrm{C}$ for $30 \mathrm{~s}$. The standard curve method and QuantStudio 7 Flex Real-Time PCR Software (Applied Biosystems, Waltham, MA) were used for data analysis. Internal control genes were GADPH, UXT, and RPS9, and their geometric mean was used to normalize the mRNA abundance data. The primer sequences of GADPH, UXT, and RPS9 were those reported by Zhou et al. (2017a). The primer sequences used in this study, verified by sequencing as described previously (Wang et al., 2012), are listed in 
Supplemental Table S1 (https://doi.org/10.3168/jds .2018-14461).

\section{Western Blotting}

Cell samples were washed 3 times with ice-cold PBS. Total protein was extracted using a mammalian protein extraction reagent (M-PER, catalog no. 78501, Thermo Fisher Scientific), which included an inhibitor cocktail (catalog no. 78442, Thermo Fisher Scientific). Two-hundred microliters of M-PER reagent (catalog no. 78501, Thermo Fisher Scientific) was added to each well and shaken gently for $5 \mathrm{~min}$. The lysate was then collected, transferred to a microcentrifuge tube, and centrifuged at $14,000 \times \mathrm{g}$ for $10 \mathrm{~min}$ at $4^{\circ} \mathrm{C}$ to pellet the cell debris. The supernatant was then transferred to a new tube before analysis. The protein concentrations were determined using BCA protein assay kit (catalog no. 23227, Thermo Fisher Scientific), and 20 $\mu \mathrm{g}$ of total protein diluted with $4 \times$ Laemmli sample buffer (catalog no.161-0747, Bio-Rad, Hercules, CA) at a ratio of $3: 1$ and boiled at $100^{\circ} \mathrm{C}$ for $10 \mathrm{~min}$. Sixty micrograms of protein was resolved by 4 to $20 \%$ Mini-Protean TGX precast gels (catalog no. 4561096, Bio-Rad) and then transferred to a polyvinylidene fluoride membrane (catalog no. 1620261, Bio-Rad) by using semi-dry transfer assembly (serial no. 221BR, Bio-Rad). The membranes were blocked with $5 \%$ skim milk in Tris-buffered saline at room temperature for $2 \mathrm{~h}$, and then incubated overnight with the primary antibodies mTOR, phosphorylated (p)-mTOR, S6K1, p-S6K1, 4EBP1, p-4EBP1 (catalog nos. 2972S, 2971S, 9202S, 9234S, 9452S, 9459S, respectively; Cell Signaling Technology, Danvers, MA), or TAS1R1 (catalog no. PA5-28771, Thermo Fisher Scientific) in blocking buffer $(1: 1,000, \mathrm{vol} / \mathrm{vol})$. After incubation with primary antibody, the membranes were subsequently washed 6 times (10 min each) and incubated with HRP AffiniPure goat anti-rabbit IgG (catalog no. ab6721; Abcam, Cambridge, UK) in Tris-buffered saline-Tween (TBST, 1:10,000, vol/vol; catalog no. 1706435, Bio-Rad) for 1 $\mathrm{h}$ at room temperature, washed 6 times (10 min each), and then incubated with the Clarity Western ECL Substrate (catalog no. 170-5060, Bio-Rad). The internal control was GAPDH (catalog no. ab22555, Abcam). Band intensities were captured using an imaging system (ChemiDoc MP, Bio-Rad) and analyzed using Image Lab 5.2.1 (Bio-Rad). The internal reference protein to normalize target protein expression was GAPDH. Total protein and phosphorylation was calculated relative to the intensity of GAPDH. Phosphorylation status was calculated as the intensity ratio of phosphorylated protein to total protein yielding arbitrary units.

\section{$\left[\mathrm{Ca}^{2+}\right]$ i Measurement}

Intracellular calcium level was measured as described previously (Song et al., 2016; Zhou et al., 2016). Briefly, the bPMEC were seeded into 96-well assay plates with black sides and a clear bottom and incubated for 24 h. Cells were starved overnight in serum-free medium before treatment with AA-free $\mathrm{KRBH}$ containing $0.1 \%$ BSA for $2 \mathrm{~h}$. Four micromoles per liter of the $\mathrm{Ca}^{2+}$-sensitive indicator dye Fluo-8 a.m. (AAT Bioquest, Sunnyvale, CA) was added for $1 \mathrm{~h}$; cells were then washed twice with Hanks' balanced salt solution (HBSS; without $\mathrm{Ca}^{2+}$; catalog no. 14175095, Gibco, Thermo Fisher Scientific). The excitation wavelength to measure $\mathrm{Ca}^{2+}$ was $490 \mathrm{~nm}$ and the emission wavelength $520 \mathrm{~nm}$. Cells were stimulated with different AA-containing media [positive control (PC): +EAA; negative control (NC): -EAA; and individual EAA supplemented to the -EAA medium] for $30 \mathrm{~min}$. Three additional wells of each treatment were used for establishing the background fluorescence (without $\mathrm{Ca}^{2+}$ ). The Fluo-8 fluorescence intensity changes for each treatment were determined with an Analyst HT plate reader (LJL BioSystems Inc., Sunnyvale, CA). Relative fluorescence units for each treatment were calculated by averaging Fluo- 8 fluorescence intensity for each treatment minus the average background fluorescence.

\section{Statistical Analysis}

All data were analyzed using the mixed model procedure of SAS (v 9.2, SAS Institute Inc., Cary, NC) according to the model

$$
Y_{i j}=\mu+T_{i}+A_{j}+e_{i j},
$$

where $\mathrm{Y}$ are observations for dependent variables, $\mu$ is the general mean, $\mathrm{T}$ is the fixed effect of treatment, $\mathrm{A}$ is the random effect of experiment day, and e is the random error. The data from + EAA and the single EAA treatments were compared with -EAA using a Dunnett test. The abundance of TAS1R1 and TAS1R 3 in mammary tissue during lactation was analyzed using the mixed procedure with repeated measures to determine effects of time. The model included the fixed effect of time $(-30,15,1,15,30,60$, and $120 \mathrm{~d}$ around parturition) and the random effect of cow. Effects of RNA interference (RNAi; control vs. siRNA), AA [PC (complete medium +EAA), NC (complete medium -EAA), or Val vs. Met] and RNAi $\times$ AA interaction on phosphorylation levels of mTOR, S6K1, and 4EBP1, $\left[\mathrm{Ca}^{2+}\right] \mathrm{i}$ level, and mRNA abundance of CSN2 in bPMEC or Mac-T cells were analyzed using PROC MIXED in a $2 \times 4$ 
factorial arrangement of treatments. Intracellular $\mathrm{Ca}^{2+}$ level was analyzed using a repeated measures ANOVA with PROC MIXED. Data are reported as least squares means \pm standard error of the means. The statistical significance level was set at $P<0.05$.

\section{RESULTS}

\section{EAA Activate mTORC1 Signaling in bPMEC}

Removing all EAA (NC, complete medium - EAA) from complete medium led to lower $(P<0.01)$ phosphorylation of mTORC1, S6K1, and 4EBP1 by 76,83 , and $80 \%$, respectively, compared with PC (complete medium +EAA; Figure 1). Compared with the -EAA cultures (NC), Arg, Val, Leu, His, Phe, Met, and Ile led to greater phosphorylation of mTORC1 by an average of $21,140,183,98,180,121$, and $32 \%(P<0.05)$, respectively. Valine, Leu, Trp, Met, and Ile also activated $(P<0.05)$ S6K1 phosphorylation by an average of $155,75,108,70$, and $79 \%$, respectively, and Val, Leu, Met, and Ile led to greater $(P<0.05) 4$ EBP1 phosphorylation by an average of $97,113,48$, and $118 \%$, respectively.

\section{Effect of EAA on the Elevation of $\left[\mathrm{Ca}^{2+}\right] \mathrm{i}$}

Incubation with complete medium (PC) led to a greater $\left[\mathrm{Ca}^{2+}\right]$ i level compared with cultures incubated with -EAA (NC; Figure 2). However, only Val or Met mixed into the -EAA medium increased levels of $\left[\mathrm{Ca}^{2+}\right]$ i. Similarly, supplementation of Val or Met increased $\left[\mathrm{Ca}^{2+}\right]$ i levels in Mac-T cells (Supplemental Figure S1; https://doi.org/10.3168/jds.2018-14461).

\section{TAS1R1 Expressed in Mammary Tissue, Mac-T Cells, and bPMEC}

Results indicate that TAS1R1 protein is expressed in Mac- $T$ cells and in the bPMEC (Figure 3a). In addition, the mRNA abundance of TAS1R1 and TAS1R3 in mammary tissue was detected at various time points during the lactation cycle by real-time PCR. Compared with the prepartum level, TAS1R1 abundance increased at $1 \mathrm{~d}$ postpartum (Figure $3 \mathrm{~b}$ ), followed by a gradual decrease in abundance by 60 and 120 d postpartum; TAS1R3 abundance followed a similar abundance pattern.

\section{Knockdown of TAS1R1 Reduced Levels of $\left[\mathrm{Ca}^{2+}\right] \mathrm{i}$}

The TAS1R1 protein abundance in the bPMEC was lower $(P<0.05)$ after a 48 -h post-siRNA transfection with si2 and si3 (Figure 4A). Compared with si-control
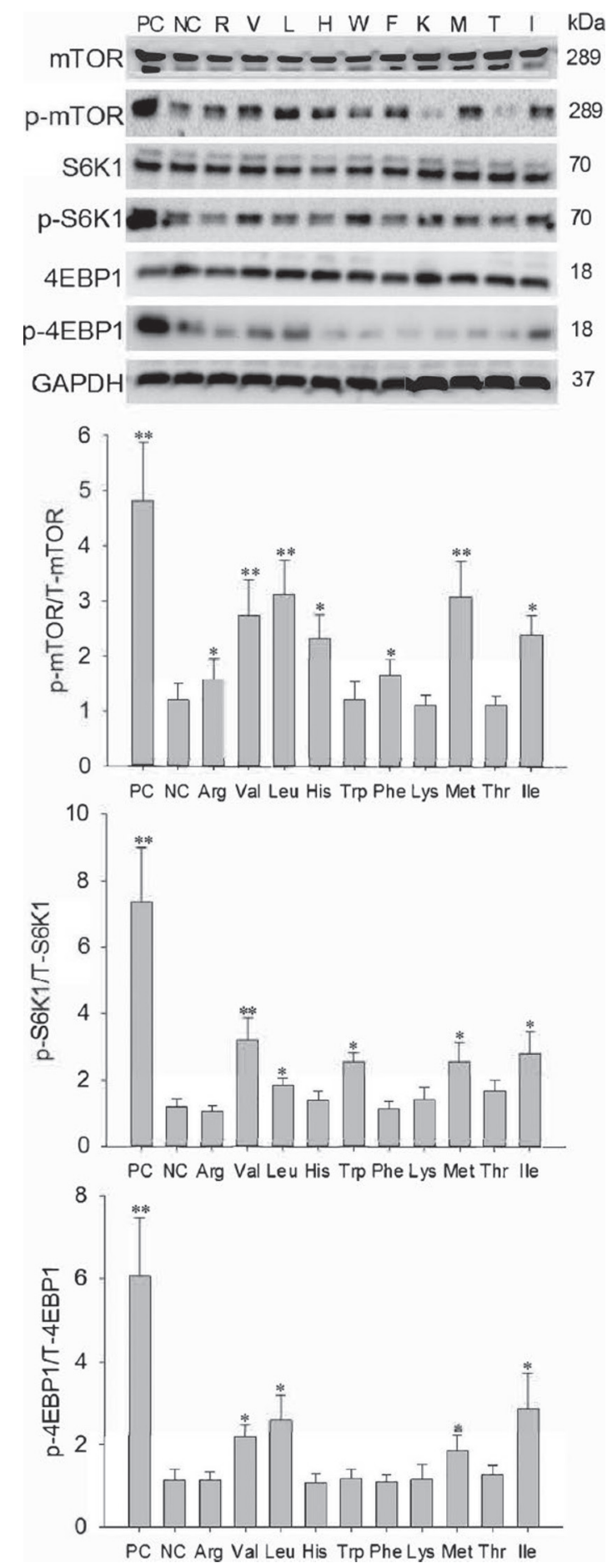

Figure 1. Amino acids activate mTORC1 in bovine mammary primary epithelial cells (bPMEC). After serum withdrawal overnight, bPMEC were incubated for $2 \mathrm{~h}$ in AA-free Krebs-Ringer's solution (KRBH) supplemented with $0.1 \%$ BSA and then stimulated with different AA for 30 min. PC = complete Dulbecco's modified Eagle's medium (DMEM) with EAA (+EAA); NC = DMEM devoid of all EAA (-EAA); R, V, L, H, W, F, K, M, T, and I = medium supplemented with arginine, valine, leucine, histidine, tryptophan, phenylalanine, lysine, methionine, threonine, or isoleucine, respectively. This experiment was repeated 3 times, and data are reported as LSM \pm SEM. Means differ from NC $(-\mathrm{EAA})$ at $* P<0.05$ or ${ }^{* *} P<0.01$. 

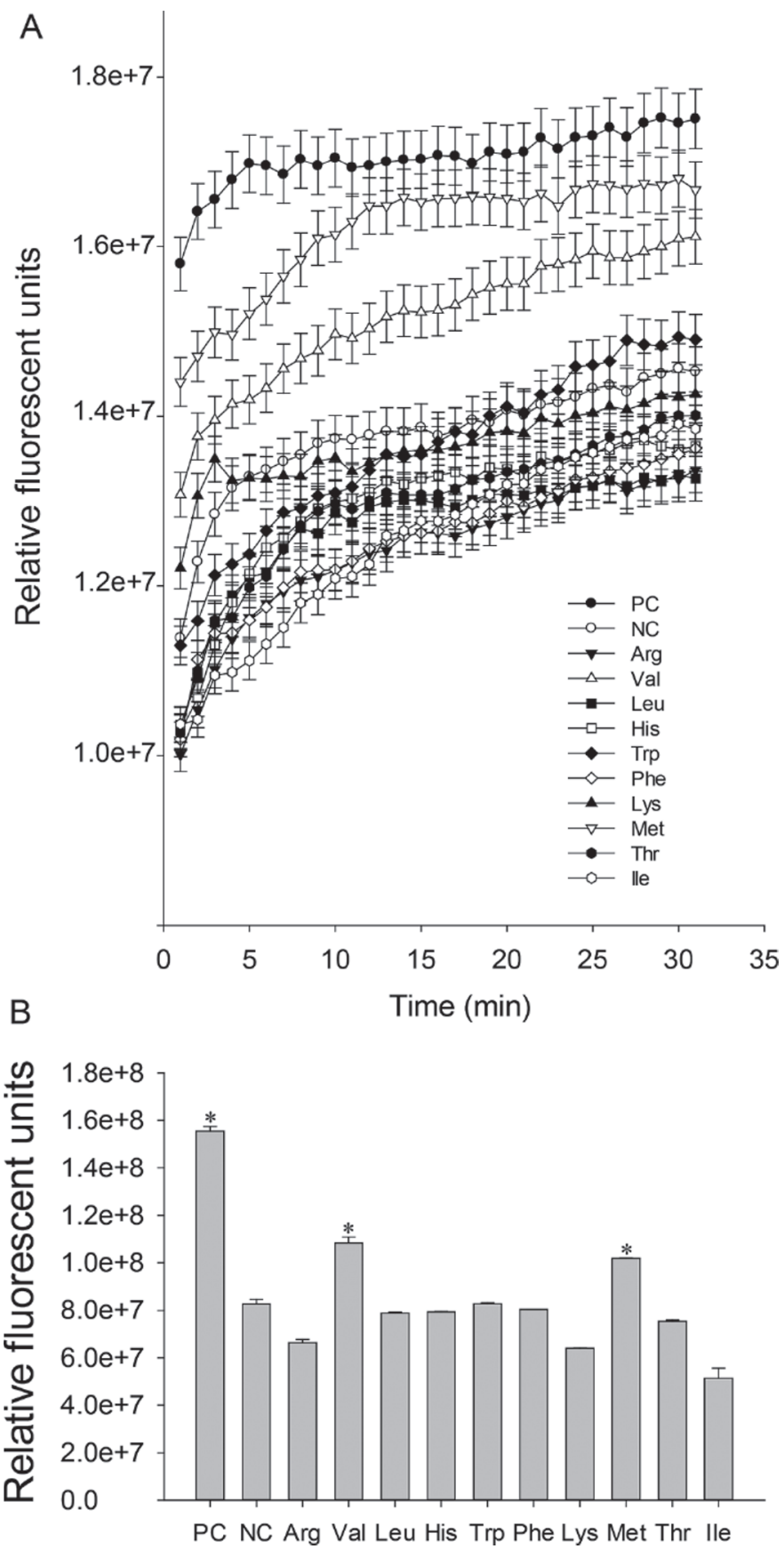

Figure 2. Amino acid availability induces intracellular calcium $\left(\left[\mathrm{Ca}^{2+}\right] \mathrm{i} ; \mathrm{A}\right)$. After serum withdrawal overnight, bovine mammary primary epithelial cells (bPMEC) were incubated for $2 \mathrm{~h}$ in AA-free Krebs-Ringer's solution supplemented with $0.1 \%$ BSA and then 4 $\mu \mathrm{mol} / \mathrm{L}$ of $\left[\mathrm{Ca}^{2+}\right]$ i-sensitive indicator dye Fluo- 8 was added for $1 \mathrm{~h}$. Cells were then washed twice with Hanks' balanced salt solution (without $\mathrm{Ca}^{2+}$ ), and stimulated with different AA-containing media. $\mathrm{PC}=$ complete Dulbecco's modified Eagle's medium (DMEM) with EAA $(+$ EAA $) ; \mathrm{NC}=$ DMEM devoid of all EAA (-EAA). Individual EAA were added to DMEM and incubated for $30 \mathrm{~min}$. The Fluo- 8 fluorescence intensity was determined with an Analyst HT plate reader (LJL BioSystems Inc., Sunnyvale, CA). This experiment was repeated 3 times, and data are reported as LSM \pm SEM. Panel B shows the average intensity values during the first $30 \mathrm{~min}$ of incubation with Fluo-8. Means differ from $\mathrm{NC}(-\mathrm{EAA})$ at $* P<0.05$. cells, si2 and si3 reduced the TAS1R1 protein abundance by 40 and $58 \%$, respectively. Thus, the si3 of TAS1R1 was used for subsequent experiments. The effects of RNAi, AA, and interactions on concentration of $\left[\mathrm{Ca}^{2+}\right] \mathrm{i}$ in bPMEC are presented in Figure 4B. The main effects of RNAi and AA and their interactions were significant $(P<0.01)$ for $\left[\mathrm{Ca}^{2+}\right]$ i level. The

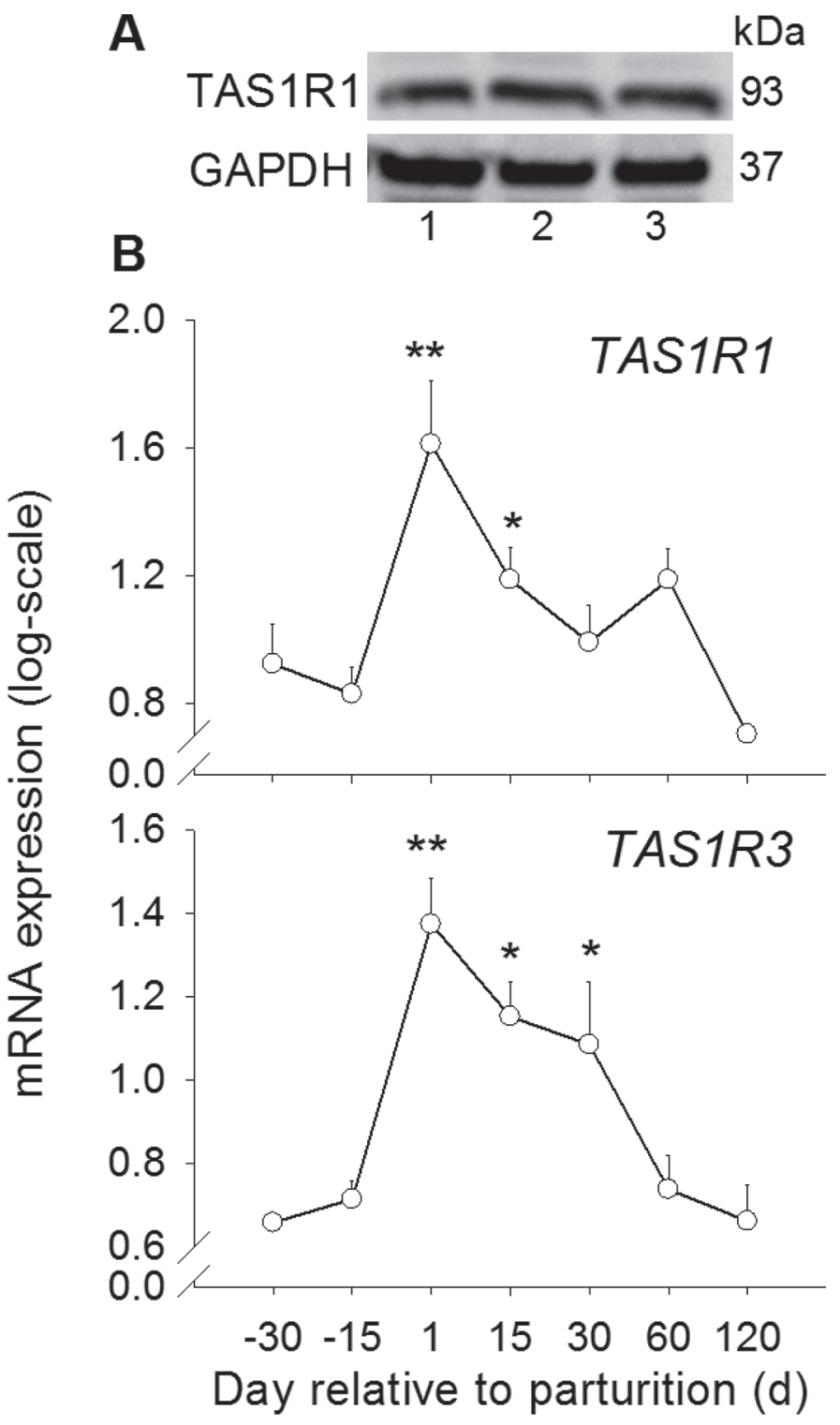

Figure 3. Abundance of taste 1 receptor member 1 (TAS1R1) in mammary gland tissue, immortalized Mac-T cells, and bovine mammary primary epithelial cells (bPMEC). (A) Protein abundance of TAS1R1 in mammary gland tissue (lane 1), immortalized bovine mammary epithelial cells, Mac-T (lane 2), and bPMEC (lane 3). (B) Mammary gland tissue mRNA abundance of TAS1R1 and TAS1R3 during the periparturient period in Holstein cows. Data are reported as LSM \pm SEM, $\mathrm{n}=7$. ${ }^{* *}$ Means differ $(P<0.01)$ from all other time points; *means differ $(P<0.05)$ from that at $-30,-15,60$, and 120 $\mathrm{d}$ around parturition. 
supplementation of Val or Met to bPMEC with the TAS1R1 knockdown resulted in reductions of 21 and $32 \%(P<0.05)$ in $\left[\mathrm{Ca}^{2+}\right]$ i levels, respectively. Similar results were detected in Mac-T cells. Compared with siRNA control, TAS1R1 knockdown decreased $(P<$ $0.05)\left[\mathrm{Ca}^{2+}\right]$ i levels when all EAA were removed from culture medium (NC). Supplementation of Val or Met also led to lower $\left[\mathrm{Ca}^{2+}\right] \mathrm{i}(P<0.05)$ by an average of 10 and 15\%, respectively (Supplemental Figure S2b; https: //doi.org/10.3168/jds.2018-14461).

\section{TAS1R1 Silencing Blocked mTOR Pathway and $\beta$-Casein Abundance}

The effects of RNAi, AA, and interactions for the phosphorylation levels of mTOR, S6K1, and 4EBP1 are presented in Figure 5. We found no RNAi $\times$ AA interaction $(P>0.05)$ for phosphorylation levels of those proteins. Compared with si-control, TAS1R1 knockdown in bPMEC led to lower $(P<0.05)$ phosphorylation of mTOR, S6K1, and 4EBP1. Compared with unsupplemented cells (NC group, -EAA), supplementation with AA resulted in greater $(P<0.05)$ mTOR, S6K1, and 4EBP1 phosphorylation. We noted main effects of both RNAi and AA $(P<0.05)$ for mRNA abundance of CNS2 (Figure 6).

In Mac-T cells, TAS1R1 knockdown led to reduced mTORC1, S6K1, and 4EBP1 phosphorylation $(P<$ 0.05) compared with the si-control; compared with unsupplemented cells (NC group, -EAA), AA supplementation also resulted in greater $(P<0.05)$ mTOR, S6K1, and 4EBP1 phosphorylation (Supplemental Figure S2a; https://doi.org/10.3168/jds.2018-14461). In addition, similar to results observed in Mac-T cells with the TAS1R1 knockdown, siRNA silencing of TAS1R1 led to lower $(P<0.05) C N S 2$ mRNA abundance in cells cultured without EAA or supplemented with Val or Met (Supplemental Figure S2c; https://doi.org/10 $.3168 /$ jds.2018-14461).

\section{DISCUSSION}

Circulating AA profiles are instrumental to the efficiency of milk protein synthesis. For mammary epithelial cells, instantly sensing alterations in extracellular AA availability is likely crucial for priming downstream protein synthesis-regulating pathways (Loor et al., 2013). Although an AA transporter-mediated regulatory role in milk protein synthesis has recently been identified (Suryawan and Davis, 2011), less is understood about upstream pathways consisting of AA-sensing components (Averous et al., 2016; Li et al., 2016, 2017).

It is now recognized that AA are sensed by membrane receptors and transmit a signal into the cell with- out being transported (Zheng et al., 2016). As a sweet taste receptor, TAS1R1/TAS1R3 is one of the GPCR capable of directly sensing AA availability by elevating $\left[\mathrm{Ca}^{2+}\right] \mathrm{i}$ concentration, which activates extracellular signal-regulated kinases 1 and 2 (ERK1/2) and, subsequently, mTORC1 signaling, a key pathway regulating protein translation (Wauson et al., 2013).
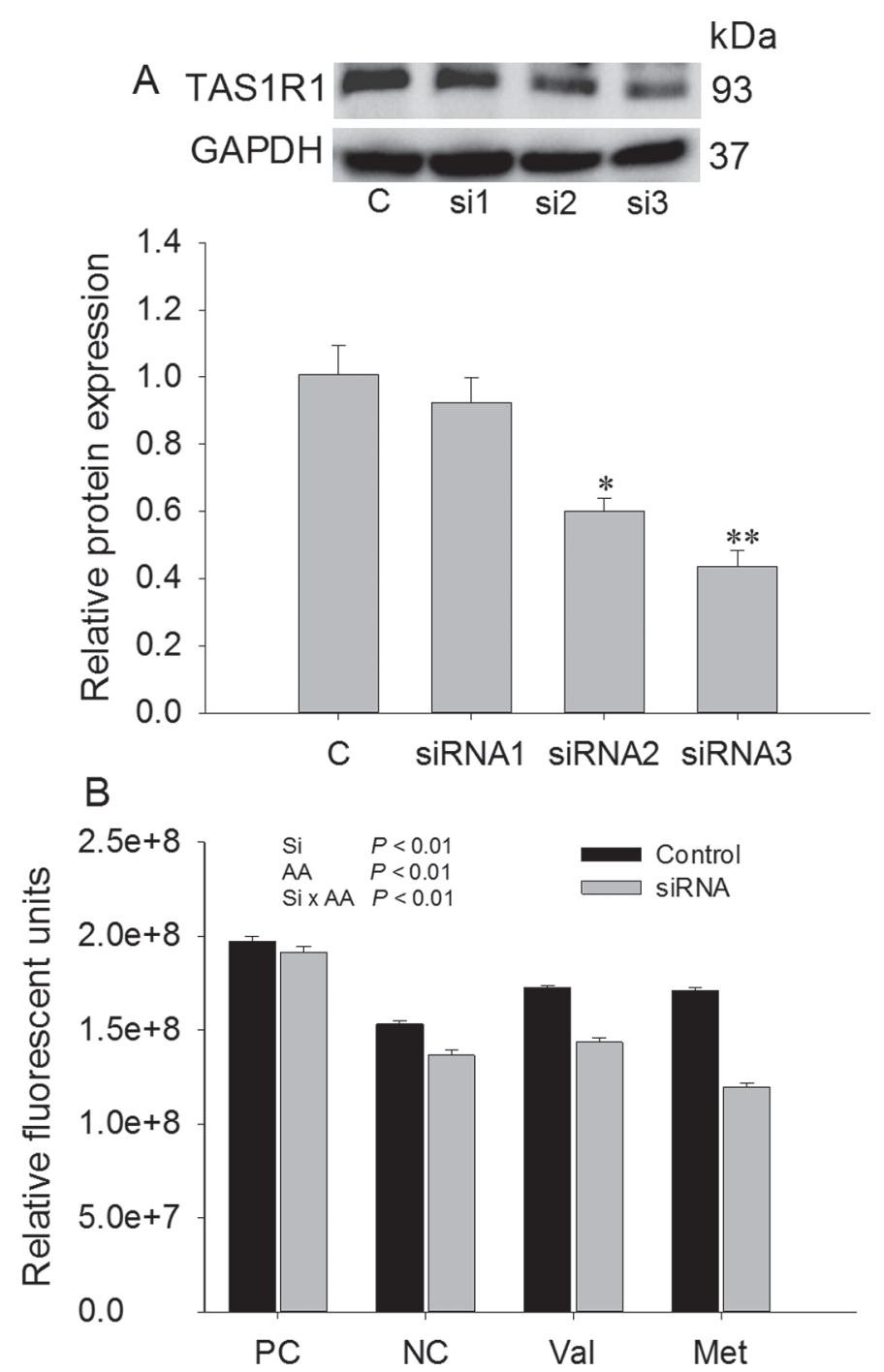

Figure 4. Knockdown of TAS1R1 attenuates Met- and Val-induced activation of intracellular calcium $\left(\left[\mathrm{Ca}^{2+}\right] \mathrm{i}\right)$ in bovine primary mammary epithelial cells (bPMEC). The bPMEC were transfected with $10 \mathrm{n} M$ scrambled oligomer (si-control) or TAS1R1 siRNA for $48 \mathrm{~h}$. (A) Protein abundance of taste 1 receptor member 1 (TAS1R1) determined by Western blotting. After transfection for $48 \mathrm{~h}$ and serum withdrawal overnight, cells were cultured in AA-free Krebs-Ringer's solution supplemented with $0.1 \%$ BSA for $2 \mathrm{~h}$ followed by addition of 4 $\mu \mathrm{mol} / \mathrm{L}$ of the $\left[\mathrm{Ca}^{2+}\right] \mathrm{i}$-sensitive indicator dye Fluo- 8 for $1 \mathrm{~h}$. Cells were then washed twice with Hanks' balanced salt solution (without $\mathrm{Ca}^{2+}$ ). (B) Cells that were subsequently stimulated with PC [containing complete Dulbecco's modified Eagle's medium (DMEM); +EAA]; NC = DMEM devoid of all EAA (-EAA); or Val or Met = supplemented individually in DMEM. This experiment was repeated 3 times, and data are reported as LSM \pm SEM. 

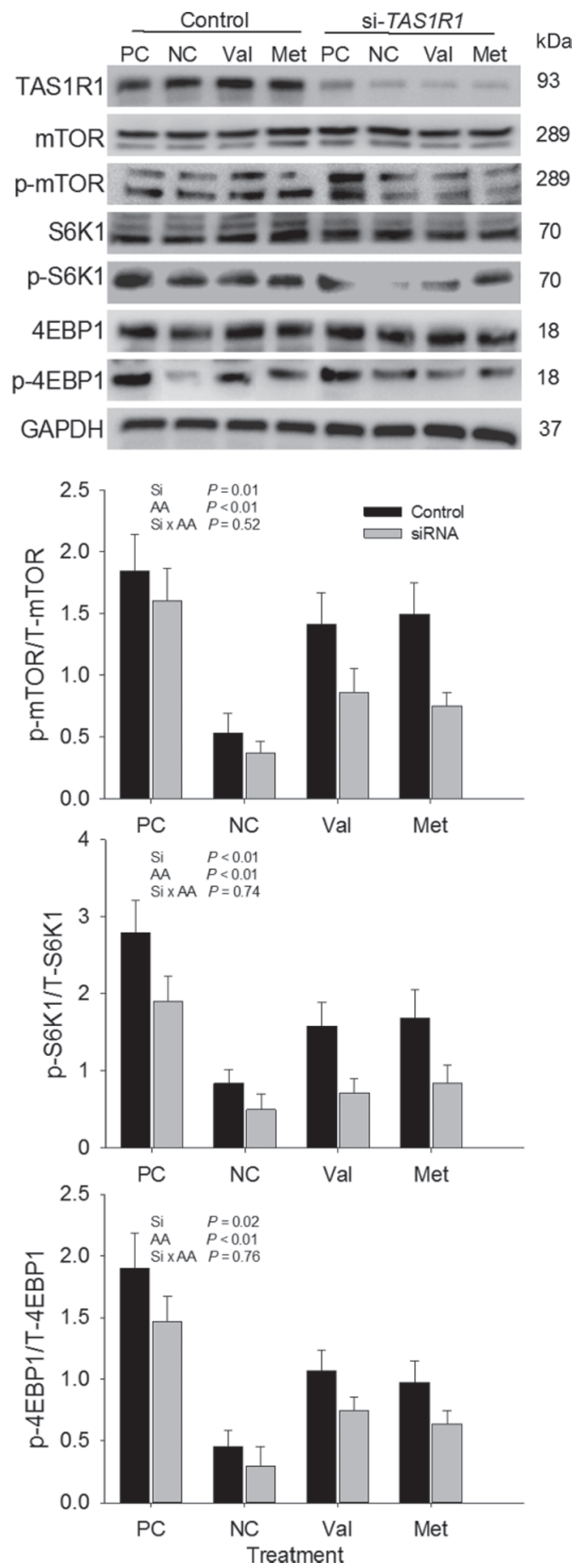

Figure 5. Methionine- and Val-induced activation of mTOR is attenuated in bovine primary mammary epithelial cells (bPMEC) with the TAS1R1 knockdown. The bPMEC was transfected with 10 $\mathrm{n} M$ scrambled oligomer (si-control) or TAS1R1 siRNA for $48 \mathrm{~h}$. After serum withdrawal overnight, cells were cultured in AA-free KrebsRinger's solution supplemented with $0.1 \%$ BSA for $2 \mathrm{~h}$. Cells were then stimulated with PC [containing complete Dulbecco's modified Eagle's medium (DMEM); +EAA]; NC = DMEM devoid of all EAA (-EAA); or Val or Met (supplemented individually in DMEM). Cells were harvested and the protein abundance of mTOR pathway determined. This experiment was repeated 3 times, and data are reported as $\mathrm{LSM} \pm \mathrm{SEM}$.

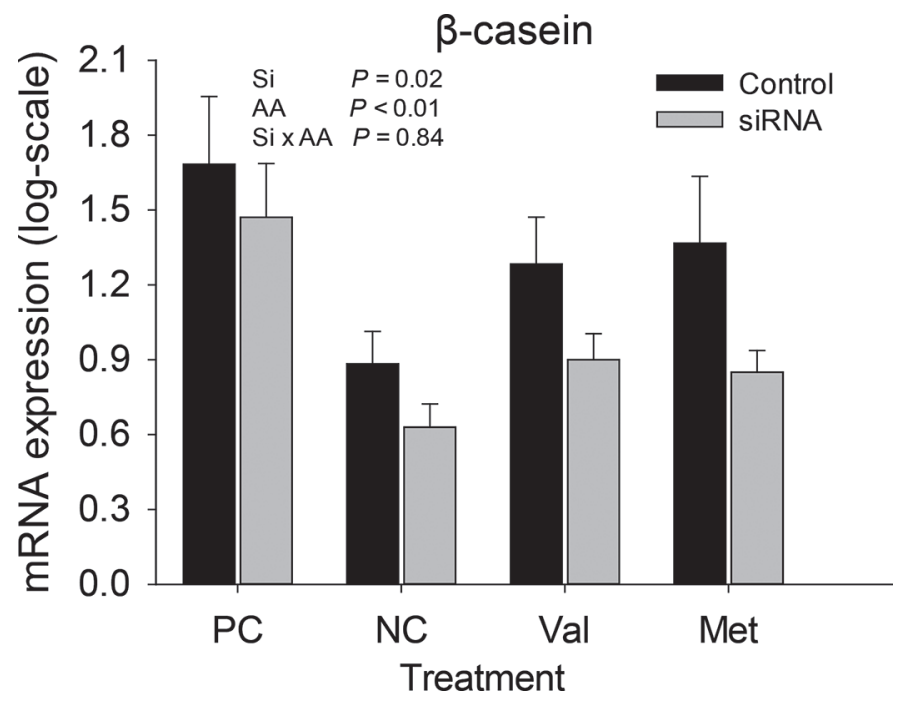

Figure 6. Taste 1 receptor member 1 (TAS1R1) knockdown repressed the mRNA abundance of $\beta$-casein in bovine primary mammary epithelial cells (bPMEC). The bPMEC were transfected with $10 \mathrm{n} M$ scrambled oligomer (si-control) or TAS1R1 siRNA for $48 \mathrm{~h}$. After serum withdrawal overnight, cells were cultured in AA-free Krebs-Ringer's solution supplemented with $0.1 \%$ BSA for $2 \mathrm{~h}$. Cells were then stimulated with lactogenic medium [lactogenic medium was devoid of fetal bovine serum and supplemented with BSA $(1 \mathrm{~g} / \mathrm{L})$ and prolactin $(2.5 \mathrm{mg} / \mathrm{L})]$, except that high glucose (HG)-DMEM was replaced with $\mathrm{PC}=$ complete Dulbecco's modified Eagle's medium (DMEM; +EAA); NC = DMEM devoid of all EAA (-EAA); of Val and Met $=$ supplemented individually in DMEM. This experiment was repeated 3 times, and data are reported as LSM \pm SEM.

The TAS1R1/TAS1R3 is broadly expressed in mouse, pig, and various types of nonruminant cultured cells (Wauson et al., 2014). The fact that TAS1R1 is also expressed in bovine mammary gland tissue, Mac-T cells, and bPMEC suggests a similar physiologic role in bovine mammary AA sensing and protein synthesis. This idea is reinforced by marked upregulation at 1 d postpartum, when mammary gland synthetic capacity increases dramatically (Bionaz et al., 2012). Thus, abundance of TAS1R1/3 coincides with enhanced mammary tissue uptake of AA soon after parturition and therefore helps coordinate milk protein synthesis (Bionaz and Loor, 2011).

Results from our group and others have identified mTORC1 signaling as the downstream target of TAS1R1/3. For instance, in HeLa cells, it was previously shown that AA induce an increase in $\left[\mathrm{Ca}^{2+}\right] \mathrm{i}$, which triggers mTORC1 and hVps34 activation (Gulati et al., 2008). Similarly, we have previously demonstrated in $\mathrm{C} 2 \mathrm{C} 12$ myotubes that activation of ERK1/2 and mTORC1 in response to AA or methionine is associated with a $\mathrm{Ca}^{2+}$-dependent shift (Zhou et al., 2016). The fact that the EAA mixture and only Val and Met increased the levels of $\left[\mathrm{Ca}^{2+}\right] \mathrm{i}$ indicates that 1 pathway through which specific AA activate mTORC1 signal- 
ing may be through $\left[\mathrm{Ca}^{2+}\right]$ i. Therefore, the observed increase in mTORC1 phosphorylation in bPMEC supplemented with all EAA, Arg, Val, Leu, His, Phe, Met, or Ile, together with greater mTORC1 and S6K1 phosphorylation with Val, Leu, Met, and Ile, support a regulatory role of T1R1/3 upstream of mTOR signaling in bPMEC.

In addition, AA can directly initiate a signaling cascade leading to the activation of mTORC1 in bovine mammary epithelial cells (Arriola Apelo et al., 2014; Liu et al., 2017). However, the fact that TAS1R1 knockdown decreased AA-induced phosphorylation of mTORC1, S6K1, and 4EBP1 in bPMEC as well as the lower levels of $\left[\mathrm{Ca}^{2+}\right] \mathrm{i}$ and $C S N 2$ abundance when TAS1R1 was knocked-down in bPMEC indicate the importance of this intracellular signal for activation of the mTORC1 pathway. Together, these data suggest that the synthesis of casein through AA is at least in part mediated by TAS1R1.

It is also worth noting that sequence differences in the TAS1R receptors within and between species (human and mouse) can significantly influence the selectivity and specificity of responses to AA (Toda et al., 2013). Heterologous abundance studies have revealed that mouse TAS1R1/TAS1R3 (mT1ASR1/mTAS1R3) is broadly activated by most L-AA (Ser, Arg, Thr, Ala, Met, Gln, and Gly), whereas human TAS1R1/ TAS1R3 (hTAS1R1/hTAS1R3) specifically responds to L-Glu and leads to an increase in $\left[\mathrm{Ca}^{2+}\right] \mathrm{i}$ ( $\mathrm{Li}$ et al., 2002; Nelson et al., 2002). In addition, the responses of mTAS1R1/mTAS1R3 to acidic AA are much weaker than other AA (Nelson et al., 2002). Our previous studies in mouse $\mathrm{C} 2 \mathrm{C} 12$ myotubes observed that TAS1R1/ TAS1R3 responds to Met and promotes mTOR signaling and protein synthesis (Zhou et al., 2016). Therefore, TAS1R1/TAS1R3-mediated regulation of mTOR might be AA-specific. The precise mechanisms that account for such differences among AA merit further research.

\section{CONCLUSIONS}

The TAS1R1/TAS1R3 in bovine mammary cells could serve as a sensor of extracellular AA, particularly Val and Met. As such, these AA could transduce signals that lead to an increase in $\left[\mathrm{Ca}^{2+}\right]$ i concentration to stimulate mTORC1. This mechanism appears to have a role in Met- and Val-induced changes in CSN2 mRNA abundance. Further in vivo studies should be performed to validate these in vitro findings.

\section{ACKNOWLEDGMENTS}

The authors thank Chen Zhang of School of Chemical Sciences, University of Illinois at Urbana-Champaign, for advice and technical help with the $\left[\mathrm{Ca}^{2+}\right] \mathrm{i}$ assay. Y. Zhou was a recipient of a postdoctoral fellowship from China Scholarship Council (CSC, Beijing) to train at the University of Illinois. Support for conduct of the experiments was provided by Hatch funds under project ILLU-538-914, National Institute of Food and Agriculture (Washington, DC).

\section{REFERENCES}

Appuhamy, J. A., N. A. Knoebel, W. A. Nayananjalie, J. Escobar, and M. D. Hanigan. 2012. Isoleucine and leucine independently regulate mTOR signaling and protein synthesis in MAC-T cells and bovine mammary tissue slices. J. Nutr. 142:484-491.

Appuhamy, J. A. D. R. N., J. R. Knapp, O. Becvar, J. Escobar, and M. D. Hanigan. 2011. Effects of jugular-infused lysine, methionine, and branched-chain amino acids on milk protein synthesis in highproducing dairy cows. J. Dairy Sci. 94:1952-1960.

Arriola Apelo, S. I., L. M. Singer, X. Y. Lin, M. L. McGilliard, N. R. St-Pierre, and M. D. Hanigan. 2014. Isoleucine, leucine, methionine, and threonine effects on mammalian target of rapamycin signaling in mammary tissue. J. Dairy Sci. 97:1047-1056.

Averous, J., S. Lambert-Langlais, F. Mesclon, V. Carraro, L. Parry, C. Jousse, A. Bruhat, A. C. Maurin, P. Pierre, C. G. Proud, and P. Fafournoux. 2016. GCN2 contributes to mTORC1 inhibition by leucine deprivation through an ATF4 independent mechanism. Sci. Rep. 6:27698.

Batistel, F., J. M. Arroyo, A. Bellingeri, L. Wang, B. Saremi, C. Parys, E. Trevisi, F. C. Cardoso, and J. J. Loor. 2017. Ethyl-cellulose rumen-protected methionine enhances performance during the periparturient period and early lactation in Holstein dairy cows. J. Dairy Sci. 100:7455-7467. https://doi.org/10.3168/jds.2017-12689.

Bionaz, M., and J. J. Loor. 2011. Gene networks driving bovine mammary protein synthesis during the lactation cycle. Bioinform. Biol. Insights 5:83-98.

Bionaz, M., K. Periasamy, S. L. Rodriguez-Zas, R. E. Everts, H. A. Lewin, W. L. Hurley, and J. J. Loor. 2012. Old and new stories: Revelations from functional analysis of the bovine mammary transcriptome during the lactation cycle. PLoS One 7:e33268.

Broderick, G. A., and R. E. Muck. 2009. Effect of alfalfa silage storage structure and rumen-protected methionine on production in lactating dairy cows. J. Dairy Sci. 92:1281-1289.

Giallongo, F., A. N. Hristov, J. Oh, T. Frederick, H. Weeks, J. Werner, H. Lapierre, R. A. Patton, A. Gehman, and C. Parys. 2015. Effects of slow-release urea and rumen-protected methionine and histidine on performance of dairy cows. J. Dairy Sci. 98:3292-3308.

Gulati, P., L. D. Gaspers, S. G. Dann, M. Joaquin, T. Nobukuni, F. Natt, S. C. Kozma, A. P. Thomas, and G. Thomas. 2008. Amino acids activate mTOR complex 1 via $\mathrm{Ca} 2+/ \mathrm{CaM}$ signaling to hVps34. Cell Metab. 7:456-465.

Kadegowda, A. K., M. Bionaz, L. S. Piperova, R. A. Erdman, and J. J. Loor. 2009a. Peroxisome proliferator-activated receptor-gamma activation and long-chain fatty acids alter lipogenic gene networks in bovine mammary epithelial cells to various extents. J. Dairy Sci. 92:4276-4289.

Kadegowda, A. K. G., M. Bionaz, L. S. Piperova, R. A. Erdman, and J. J. Loor. 2009b. Peroxisome proliferator-activated receptorgamma activation and long-chain fatty acids alter lipogenic gene networks in bovine mammary epithelial cells to various extents. J. Dairy Sci. 92:4276-4289.

Lee, C., A. N. Hristov, T. W. Cassidy, K. S. Heyler, H. Lapierre, G. A. Varga, M. J. de Veth, R. A. Patton, and C. Parys. 2012. Rumenprotected lysine, methionine, and histidine increase milk protein yield in dairy cows fed a metabolizable protein-deficient diet. J. Dairy Sci. 95:6042-6056.

Li, S., A. Hosseini, M. Danes, C. Jacometo, J. Liu, and J. J. Loor. 2016. Essential amino acid ratios and mTOR affect lipogenic gene networks and miRNA expression in bovine mammary epithelial cells. J. Anim. Sci. Biotechnol. 7:44. 
Li, S. S., J. J. Loor, H. Y. Liu, L. Liu, A. Hosseini, W. S. Zhao, and J. X. Liu. 2017. Optimal ratios of essential amino acids stimulate beta-casein synthesis via activation of the mammalian target of rapamycin signaling pathway in MAC-T cells and bovine mammary tissue explants. J. Dairy Sci. 100:6676-6688.

Li, X., L. Staszewski, H. Xu, K. Durick, M. Zoller, and E. Adler. 2002. Human receptors for sweet and umami taste. Proc. Natl. Acad. Sci. USA 99:4692-4696.

Loor, J. J., M. Bionaz, and J. K. Drackley. 2013. Systems physiology in dairy cattle: Nutritional genomics and beyond. Annu. Rev. Anim. Biosci. 1:365-392. https://doi.org/10.1146/annurev-animal -031412-103728.

Liu, G. M., M. D. Hanigan, X. Y. Lin, K. Zhao, F. G. Jiang, R. R. White, Y. Wang, Z. Y. Hu, and Z. H. Wang. 2017. Methionine, leucine, isoleucine, or threonine effects on mammary cell signaling and pup growth in lactating mice. J. Dairy Sci. 100:4038-4050.

Luo, C., S. Zhao, M. Zhang, Y. Gao, J. Wang, M. D. Hanigan, and N. Zheng. 2018. SESN2 negatively regulates cell proliferation and casein synthesis by inhibition the amino acid-mediated mTORC1 pathway in cow mammary epithelial cells. Sci. Rep. 8:3912.

Monirujjaman, M., and A. Ferdouse. 2014. Metabolic and physiological roles of branched-chain amino acids. Adv. Mol. Biol. 2014:364976.

Nelson, G., J. Chandrashekar, M. A. Hoon, L. X. Feng, G. Zhao, N. J. P. Ryba, and C. S. Zuker. 2002. An amino-acid taste receptor. Nature 416:199-202.

Nichols, J. R., D. J. Schingoethe, H. A. Maiga, M. J. Brouk, and M. S. Piepenbrink. 1998. Evaluation of corn distillers grains and ruminally protected lysine and methionine for lactating dairy cows. J. Dairy Sci. 81:482-491.

Ordway, R. S., S. E. Boucher, N. L. Whitehouse, C. G. Schwab, and B. K. Sloan. 2009. Effects of providing two forms of supplemental methionine to periparturient Holstein dairy cows on feed intake and lactational performance. J. Dairy Sci. 92:5154-5166.

Osorio, J. S., P. Ji, J. K. Drackley, D. Luchini, and J. J. Loor. 2013. Supplemental Smartamine M or MetaSmart during the transition period benefits postpartal cow performance and blood neutrophil function. J. Dairy Sci. 96:6248-6263. https://doi.org/10.3168/jds 2012-5790.

Osorio, J. S., P. Ji, J. K. Drackley, D. Luchini, and J. J. Loor. 2014. Smartamine $\mathrm{M}$ and MetaSmart supplementation during the peripartal period alter hepatic expression of gene networks in 1-carbon metabolism, inflammation, oxidative stress, and the growth hormone-insulin-like growth factor 1 axis pathways. J. Dairy Sci. 97:7451-7464.

Overton, T. R., L. S. Emmert, and J. H. Clark. 1998. Effects of source of carbohydrate and protein and rumen-protected methionine on performance of cows. J. Dairy Sci. 81:221-228.

Patton, R. A. 2010. Effect of rumen-protected methionine on feed intake, milk production, true milk protein concentration, and true milk protein yield, and the factors that influence these effects: a meta-analysis. J. Dairy Sci. 93:2105-2118.

Shennan, D. B., D. T. Calvert, F. R. Backwell, and C. A. Boyd. 1998. Peptide aminonitrogen transport by the lactating rat mammary gland. Biochim. Biophys. Acta 1373:252-260.

Socha, M. T., D. E. Putnam, B. D. Garthwaite, N. L. Whitehouse, N. A. Kierstead, C. G. Schwab, G. A. Ducharme, and J. C. Robert.
2005. Improving intestinal amino acid supply of pre- and postpartum dairy cows with rumen-protected methionine and lysine. J. Dairy Sci. 88:1113-1126.

Song, T., Y. Zhou, J. Peng, Y. X. Tao, Y. Yang, T. Xu, J. Peng, J. Ren, Q. Xiang, and H. Wei. 2016. GPR120 promotes adipogenesis through intracellular calcium and extracellular signal-regulated kinase 1/2 signal pathway. Mol. Cell. Endocrinol. 434:1-13.

Suryawan, A., and T. A. Davis. 2011. Regulation of protein synthesis by amino acids in muscle of neonates. Front. Biosci. (Landmark Ed.) $16: 1445-1460$.

Toda, Y., T. Nakagita, T. Hayakawa, S. Okada, M. Narukawa, H. Imai, Y. Ishimaru, and T. Misaka. 2013. Two distinct determinants of ligand specificity in T1R1/T1R3 (the umami taste receptor). J. Biol. Chem. 288:36863-36877.

Trinacty, J., L. Krizova, M. Richter, V. Cerny, and J. Riha. 2009. Effect of rumen-protected methionine, lysine or both on milk production and plasma amino acids of high-yielding dairy cows. Czech J. Anim. Sci. 54:239-248.

Wang, X., and C. G. Proud. 2006. The mTOR pathway in the control of protein synthesis. Physiology (Bethesda) 21:362-369.

Wang, Y., J. Liu, H. Wu, X. Fang, H. Chen, and C. Zhang. 2017. Amino acids regulate mTOR pathway and milk protein synthesis in a mouse mammary epithelial cell line is partly mediated by T1R1/T1R3. Eur. J. Nutr. 56:2467-2474.

Wang, M., S. Moisá, M. J. Khan, J. Wang, D. Bu, and J. J. Loor. 2012. MicroRNA expression patterns in the bovine mammary gland are affected by stage of lactation. J. Dairy Sci. 95:6529-6535. https:// doi.org/10.3168/jds.2012-5748.

Wauson, E. M., H. A. Dbouk, A. B. Ghosh, and M. H. Cobb. 2014. G protein-coupled receptors and the regulation of autophagy. Trends Endocrinol. Metab. 25:274-282.

Wauson, E. M., M. L. Guerra, J. Dyachok, K. McGlynn, J. Giles, E. M. Ross, and M. H. Cobb. 2015. Differential regulation of ERK1/2 and mTORC1 through T1R1/T1R3 in MIN6 cells. Mol. Endocrinol. 29:1114-1122.

Wauson, E. M., A. Lorente-Rodriguez, and M. H. Cobb. 2013. Minireview: Nutrient sensing by G protein-coupled receptors. Mol. Endocrinol. 27:1188-1197.

Zheng, L., W. Zhang, Y. F. Zhou, F. N. Li, H. K. Wei, and J. Peng. 2016. Recent advances in understanding amino acid sensing mechanisms that regulate mTORC1. Int. J. Mol. Sci. 17:1636.

Zhou, Y., J. Ren, T. Song, J. Peng, and H. Wei. 2016. Methionine regulates mTORC1 via the T1R1/T1R3-PLCbeta-Ca2+-ERK1/2 signal transduction process in C2C12 cells. Int. J. Mol. Sci. 17:1684.

Zhou, Z. T. A. Garrow, X. W. Dong, D. N. Luchini, and J. J. Loor. 2017a. Hepatic activity and transcription of betaine-homocysteine methyltransferase, methionine synthase, and cystathionine synthase in periparturient dairy cows are altered to different extents by supply of methionine and choline. J. Nutr. 147:11-19.

Zhou, Z., E. Trevisi, D. N. Luchini, and J. J. Loor. 2017b. Differences in liver functionality indexes in peripartal dairy cows fed rumenprotected methionine or choline are associated with performance, oxidative stress status, and plasma amino acid profiles. J. Dairy Sci. 100:6720-6732. 